\title{
How to Get Away with Spreading COVID-19: Political Connections and Pandemic Response
}

\author{
Robert Kubinec, Haillie Lee, and Andrey Tomashevskiy
}

December 21, 2020

\begin{abstract}
While the aim of COVID-19 policies is to suppress the pandemic, many fear that the burden of the restrictions will fall more heavily on less privileged groups. We show one potential mechanism for COVID-19 responses to increase inequality by examining the intersection of business restrictions and business political connections. Using an online survey of 2,735 business employees and managers in Ukraine, Egypt and Venezuela over the summer of 2020, we show that businesses with political connections to government officials were significantly less likely to shut down as a result of COVID-19 policies. This finding suggests that measures designed to mitigate Covid-19 are less effective in countries with a weak rule of law if politically connected firms are able to circumvent restrictions by leveraging political connections to receive preferential treatment. In addition, politically-connected firms are no more likely-and sometimes even less likely-to engage in social-distancing policies to mitigate the pandemic despite the fact that they are more likely to remain open. ${ }^{1}$
\end{abstract}

\footnotetext{
${ }^{1}$ We thank Laron Williams and participants in the Public Policy, Opinions, Behavior, and Health Outcomes during the COVID Pandemic conference for helpful comments on this draft.
} 


\section{Introduction}

While public health experts have called for restrictive measures to combat COVID-19, as is so often the case, government leaders have often chosen to interpret these restrictions as best fits their interests. While an increasing amount of research has shown how COVID-19's economic effects have fallen more harshly on lower-income individuals (Bonaccorsi, Pierri, Cinelli, Flori, Galeazzi, Porcelli, Schmidt, Valensise, Scala, Quattrociocchi and Pammolli 2020; Adams-Prassl, Boneva, Golin and Rauh 2020), relatively little is known about whether similar distortions exist among companies. From an efficiency standpoint, the companies that should bear the burden of COVID-19 restrictions are those with extra cash on hand and stable lines of credit to withstand the disruption to their basis. However, we contend in this paper that companies can instead employ political connections to circumvent COVID19 restrictions so that businesses without connections bear the brunt of policies designed to fight the pandemic. As we study these issues in countries known to have high levels of corruption and relatively weak state institutions, we believe that these same issues are likely occurring in other countries that lack strong and autonomous states.

To establish how politically-connected companies have been differentially affected by COVID-19, we implemented an online survey of 2,567 business employees and managers in Ukraine, Venezuela and Egypt during the late spring and summer of 2020. Our rich dataset includes multiple measures for corporate political connections, the history of company interaction with bureaucrats (negative and positive), as well as patterns of political activity such as funding campaigns, ordering employees to vote for candidates and holding rallies on behalf of political parties. By combining this historical data on companies with questions about their compliance with COVID-19 directives, we are able to understand with considerable precision to what extent political connections enable companies to avoid pandemic-related business restrictions.

The results are not encouraging in terms of the fairness of COVID-19 policy implementation. We show that the politically connections of companies, measured either via self-reported 
scales or in terms of observed linkages between politicians and the company, are highly correlated with companies staying open during the pandemic. These companies also tend to be larger on average. However, while it might be expected that these companies would be more likely to implement social-distancing and other measures for employees considering that they remained open, we find that this is not the case, and for some types of social distancing measures, politically-connected firms' employees are less likely to comply. For this reason, we argue that companies are employing political connections to insulate themselves from COVID-19 restrictions, potentially increasing infections in their countries and passing the burden of business restrictions to less-connected, smaller and more vulnerable businesses. This outcome has both equity and welfare consequences as politically-connected firms are not necessarily those which should remain open from an efficiency standpoint.

This research also makes contributions to research on disaster response in governments with extensive corruption (Atkinson, Hicken and Ravanilla 2014; Anbarci, Escaleras and Register 2005; Escaleras, Anbarci and Register 2007). Our results speak to a growing literature on the relationship between politics, corruption, and disaster response. This study suggests that governments with weak rule of law where state-business relations are driven by informal ties are less effective in implementing public policy responses to disruptive natural events such as the COVID-19 pandemic. Our findings also contribute to the literature on politically connected firms; we show that political connected firms can capture a larger market share through preferential access access to club goods, such as exemptions from public health restrictions (Fisman 2001; Faccio, Masulis and McConnell 2006). Firms' heterogeneous experiences in accessing such club goods raise questions concerning the relationship between state-business ties and inequality in high-corruption states. 


\section{Pandemics and Political Connections}

Relatively soon after the pandemic started, a massive scholarly enterprise to measure the economic consequences of COVID-19 restrictions put out a steady stream of studies. While many if not most of these papers remain unpublished, and the ever-expanding literature is difficult to characterize, we can already make some summary statements about how and to what extent COVID-19 restrictions affected businesses. Brodeur, Gray, Islam and Bhuiyan (2020) offer the most rigorous overview of this research, revealing that business restrictions have had profound negative consequences for companies and their employees. At one point early in the pandemic, each additional 10 days of lockdown restrictions was associated with a 1.7 percent increase in unemployment in the United States (Brodeur et al. 2020, 28). These numbers are unheard of outside of massive natural disasters like tsunamis and earthquakes. In addition to the direct effect of policies, there are also indirect effects as consumers fear becoming infected with the virus, choosing on their own to avoid retail establishments and restaurants. Long-term, uncertainty over the state of the economy and the pandemic can depress investment and lead to chronic unemployment depending on how the recovery from the pandemic unfolds, assuming the pandemic ends at some point in the near future (Brodeur et al. 2020, 27).

For these reasons, the pandemic poses a mortal threat to many companies, though some will be much more affected than others in the immediate aftermath of the pandemic. For example, Bartik, Bertrand, Cullen, Glaeser, Luca and Stanton (2020) revealed that as many as $53 \%$ of U.S. retail and $70 \%$ of arts and entertainment businesses were closed as of the first week of April 2020. However, only $19 \%$ of financial firms and $21 \%$ of professional services firms reported closing. As such, the impacts of the early restrictions on COVID-19 were highly heterogeneous and very detrimental to certain industries, though over time we expect the macroeconomic shockwaves to hurt the performance of companies originally left unscathed.

This heterogeneity in the effect of COVID-19 on companies parallels the unequal effects of the pandemic on workers. While there has been an overall deterioration in labor market, 
lockdown policies have hurt the working poor more severely (Adams-Prassl et al. 2020). Workers who rely on daily wages and in-person work have been more severely affected by travel restrictions Bonaccorsi et al. (2020). On the other hand, workers who are able to work remotely from home, in many cases high-income earners, have been affected in a more limited manner by the pandemic.

Given the severity of the effects of COVID-19 restrictions on business, it makes sense that these businesses would seek loopholes and other ways of circumventing restrictions. At present, however, we have only informative yet isolated examples of businesses taking advantage of COVID-19. In one case, a former U.S. political fundraiser reached deals to sell roughly $\$ 630$ million in Covid-19 medical supplies to government entities after using Republican political connections to facilitate business, according to emails and contract documents. ${ }^{2}$ During summer 2020 Congressional Democrats sent a letter to the Trump administration complaining about other contracts, including mask production and test tubes, which were allegedly made to well-connected businesspeople. ${ }^{3}$ In a different vein, Brazilian President Bolsonaro has spared evangelical churches from COVID-19 restrictions, which many believe is due to the political connections of this group. ${ }^{4}$ These data points, while individually isolated, at least demonstrate the ease with which COVID-19 policies can be manipulated to the benefit of well-connected allies.

We can expect that the ability of businesses to circumvent restrictions is a function of state capabilities, potential customer blowback and business' beliefs about what their competitors might be doing. Customer preferences are often indeterminate as some customers would prefer more social distancing while others prefer less, rendering the market an ineffective check on business behavior. Knowledge of what other businesses are doing undoubtedly plays a role in business compliance via coordination games and strategic complements, but it is relatively difficult to know exactly how these beliefs change. Ultimately, the variable

\footnotetext{
${ }^{2}$ See https://www.wsj.com/articles/coronavirus-gear-broker-used-political-ties-to-sell-goods-to-states-data-show-115948

${ }^{3}$ See https://thehill.com/policy/healthcare/507471-house-panel-probes-problematic-government-contracts-covid-19-supp

${ }^{4}$ See https://www.ft.com/content/7c3a17c6-f130-4659-972f-0fe9ebc7102b
} 
with the clearest positive or negative effect on business behavior are state policies mandating compliance.

While the COVID-19 pandemic is a new phenomenon, business attempts to circumvent state policies designed to counteract natural and other disasters are certainly not. To the extent that COVID-19 restrictions impose costs on businesses, firms have an interest in minimizing the negative impact of these policies. Firms' degree of success in escaping the costs of restrictions depends to a large extent on state-business relations. In governments with weak institutions, weak traditions of the rule of law and high levels of corruption, statebusiness relations are characterized by a high degree of informality (Fisman 2001; Faccio, Masulis and McConnell 2006; Shleifer and Vishny 1993). Interactions between firms and government agents are affected by informal connections, such as family, clan or geographical ties, professional and political histories of its owners and board members, or ongoing informal/extralegal financial exchanges between the firm and government agents. Research shows that firms' experiences in high-corruption states vary as a function of the strength and effectiveness of their political connections (Claessens, Feijen and Laeven 2008; Khwaja and Mian 2005). This is reflected not only in preferential access to private goods such as government loans, but also in access to club goods, such as exemptions from government regulations.

Research shows that the existence of these types of politically connected club goods directly affects disaster response in high-corruption states (Atkinson, Hicken and Ravanilla 2014; Anbarci, Escaleras and Register 2005; Escaleras, Anbarci and Register 2007; Whittaker, Frühauf, Burthem, Parry, Kotikalapudi, Liang, Barker, Patel and Kelman 2018; Ambraseys and Bilham 2011). Since politically connected firms can evade enforcement of government standards, corrupt governments are associated with high earthquake fatalities due to widespread substandard construction practices. Political connections and informal relationships also play a role in the distribution of disaster aid. With respect to COVID-19 restrictions, it is reasonable to expect that a similar pattern will hold, and there is some 
evidence suggesting that informality and cronyism has worsened as a result of overwhelmed bureaucracies (Gallego, Prem and Vargas 2020).

Based on this research, we believe that politically connected firms should be able to leverage their political connections to bypass lockdown restrictions and remain open. Politically connected firms may also be less likely to comply with less stringent restrictions, such as limited customer/employee capacity. Since politically unconnected firms are more likely to

comply with restrictions and shut down or reduce their capacity and output, connected firms are then positioned to capture a larger share of the market. Given that political connections often derive from social relations stratified by resource inequalities, we believe that it is more likely that re-distribution of market opportunities to these companies will exacerbate existing wealth and income inequalities.

Based on this prior research, we propose two hypotheses that reflect how political connections may enable companies to evade COVID-19 restrictions:

H1: Companies with more political connections are less likely to shut down due to COVID-19 restrictions than non-connected businesses.

H2: Companies with more political connections are no more likely to implement internal policies mandating social distancing than non-connected businesses.

\section{Data}

Our data come from an online survey conducted in Egypt, Ukraine and Venezuela during the summer of 2020. All three countries implemented wide-reaching lockdown measures in March and April 2020 to combat the spread of COVID-19. From mid-March to the end of April, Ukraine and Egypt required all non-essential business to shut down. In Ukraine, only grocery stores, pharmacies, banks, and gas stations were permitted to remain open. Egypt similarly required businesses in the entertainment, retail, hospitality, and other service 
industries to shut down. Venezuela implemented a more restrictive lockdown, regulating the movement of individuals as well as mandating the shutdown of all non-essential businesses. Elements of these lockdown policies remained in place until July 2020 (Cheng, Barcelo, Hartnett, Kubinec and Messerschmidt 2020).

Egypt, Ukraine and Venezuela are useful cases for this type of analysis since these are high-corruption countries where firms face incentives to develop connections to government agents as protection from government predation (Diwan, Keefer and Schiffbauer 2015). There is also some institutional variance since Ukraine is a weak democracy, and Egypt and Venezuela are authoritarian regimes. To recruit respondents, we employed Facebook ad targeting at business managers and employees. This targeting method is quite similar to business-to-business marketing strategies and is seen as an excellent way to reach managers directly rather than have to use phone or email methods that are prone to being ignored by businesses. Furthermore, Facebook ads allow managers to access the survey apart from their work, permitting plausible anonymity that conventional firm surveys cannot provide.

In total we recruited 2,735 respondents who answered at least one of our COVID-19 related questions. A plot showing the distribution of responses by country and industry is shown in Figure 8. This figure shows that there is heterogeneity across countries, although pronounced concentrations in retail, transportation, health care and education. This is not surprising as these sectors tend to absorb a lot of labor and firms. Manufacturing is relatively low in Egypt and Venezuela but much higher in Ukraine. Given this heterogeneity in sector, we think it is important to control for sector in all analyses as it represents potential sample selection bias.

Figure 2 shows the proportion of managers versus employees in the different samples. As can be seen, these values are quite similar across countries. Managers represent 30 to 40 percent of individual samples, reflecting the survey targeting towards higher-ups in companies. At the same time, it should be noted that the majority of the sample are employees. For the purposes of this study, both employees and managers should have access to relevant 


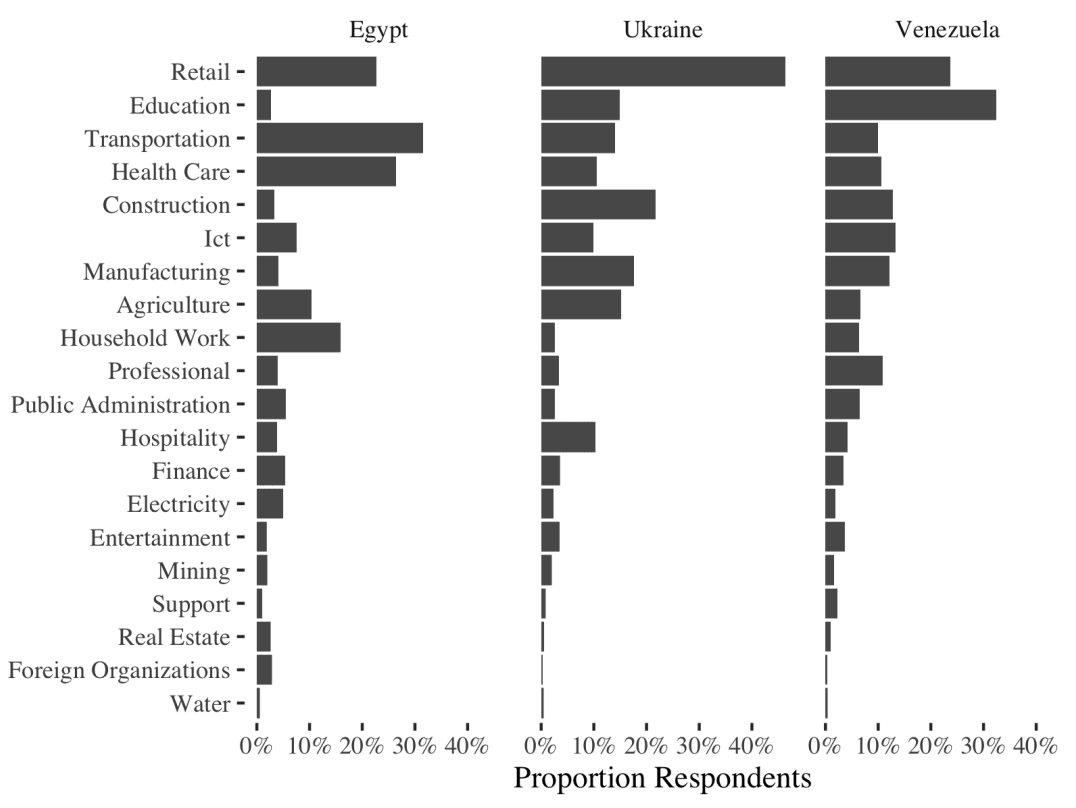

Figure 1: Distribution of Respondents by Sector

information, such as whether their firm implements social distancing and whether the firm shut down due to the COVID-19 pandemic.

In this survey, our main information about a company's response to COVID-19 comes from a series of questions that are shown in Table 1. As can be seen, we have data both for whether the company shut down due to COVID-19 restrictions and internal company enforcement of prudent social-distancing and mask-wearing policies. The modal responses for these questions communicate some of the staggering effects of these policies on businesses: the majority of the sample reports that their company had to shut down due to COVID-19 restrictions at some point. At the same time, a plurality of respondents still maintain that the government could do more to combat COVID-19 in their country.

To measure political connections, we use both a self-assessment scale for connections in addition to more objective linkages between the company and the state. The self-assessed scale is a 0 to 10 slider that respondents place their company on, where 0 equals no known political connections and 10 equals as connected as possible. The observed or objective linkages are answers to a range of questions that asked respondents whether their company 


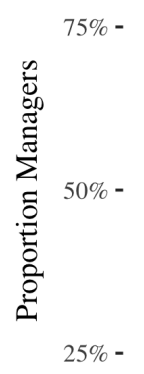

$0 \%-$
Egypt
Ukraine
Venezuela

Figure 2: Proportion Managers by Country

Table 1: COVID-19 Questions in Survey

\begin{tabular}{lll}
\hline Question & Answers & Modal Response \\
\hline $\begin{array}{l}\text { How satisfied are you with your } \\
\text { government's response to the COVID-19 } \\
\text { epidemic? }\end{array}$ & 3-category Likert & Government is doing too little (43\%) \\
$\begin{array}{l}\text { Has your company had to close down due } \\
\text { to COVID-19 restrictions? }\end{array}$ & Yes/No & Yes (52\%) \\
$\begin{array}{l}\text { How closely have employees been } \\
\text { following thes policies: face masks, } \\
\text { maintaining } 2 \text { meters space, working at } \\
\text { home, no group meetings }\end{array}$ & All/some/none & Face masks (73\% compliance) \\
$\begin{array}{l}\text { If your company has a warehouse or } \\
\text { factory, how has your company changed } \\
\text { working conditions in response to }\end{array}$ & $\begin{array}{l}\text { The same/No. employees restricted/No } \\
\text { COVID-19? }\end{array}$ & No. restricted (51\%) \\
\hline
\end{tabular}

had managers, board members or owners had specific types of relationship to the state. The question can be seen in Figure 3, revealing the wide array of options presented to the respondent.

Because this question produced a large number of indicators, aggregation is necessary to use it as a predictor variable. To do so, we constructed a one-dimensional scale by employing an item-response theory model and aggregating the data to the sum of the number of connections for each type of officer in the company (i.e., the rows in Figure 3). Correlation 


\section{Does your firm have any of the following?}

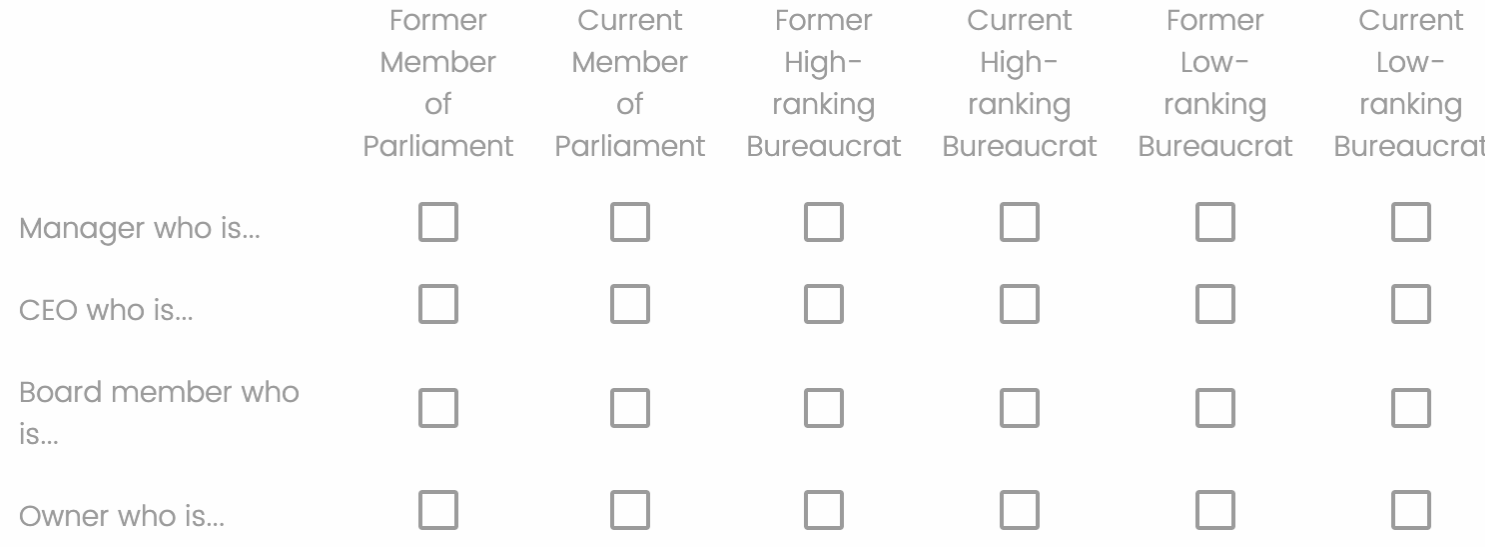

Figure 3: Respondent Question for Observed Linkages Between Company and State

between this constructed measure and the self-reported score is reasonably high at 0.47 , indicating both measures are likely tapping into the same concept although there are still clear differences between them.

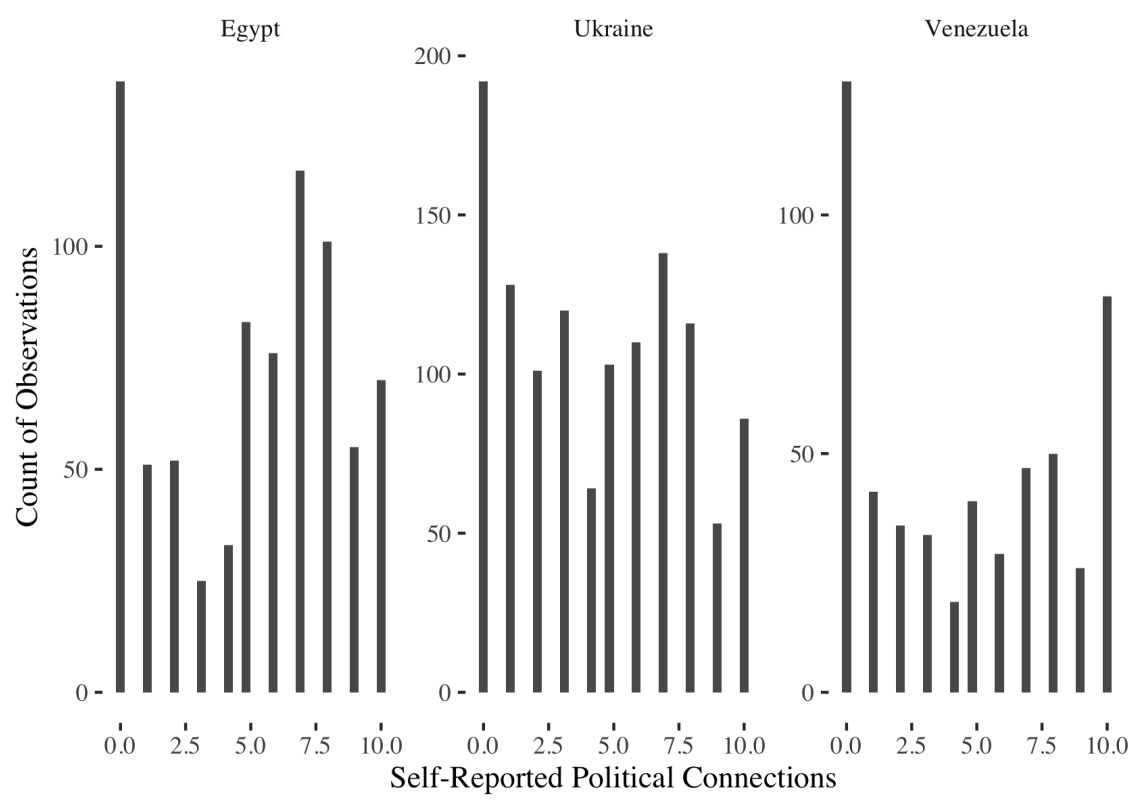

Figure 4: Histogram by Country for Self-Reported Political Connections Score

This produced a single-dimensional score for each company. Histograms for the self- 


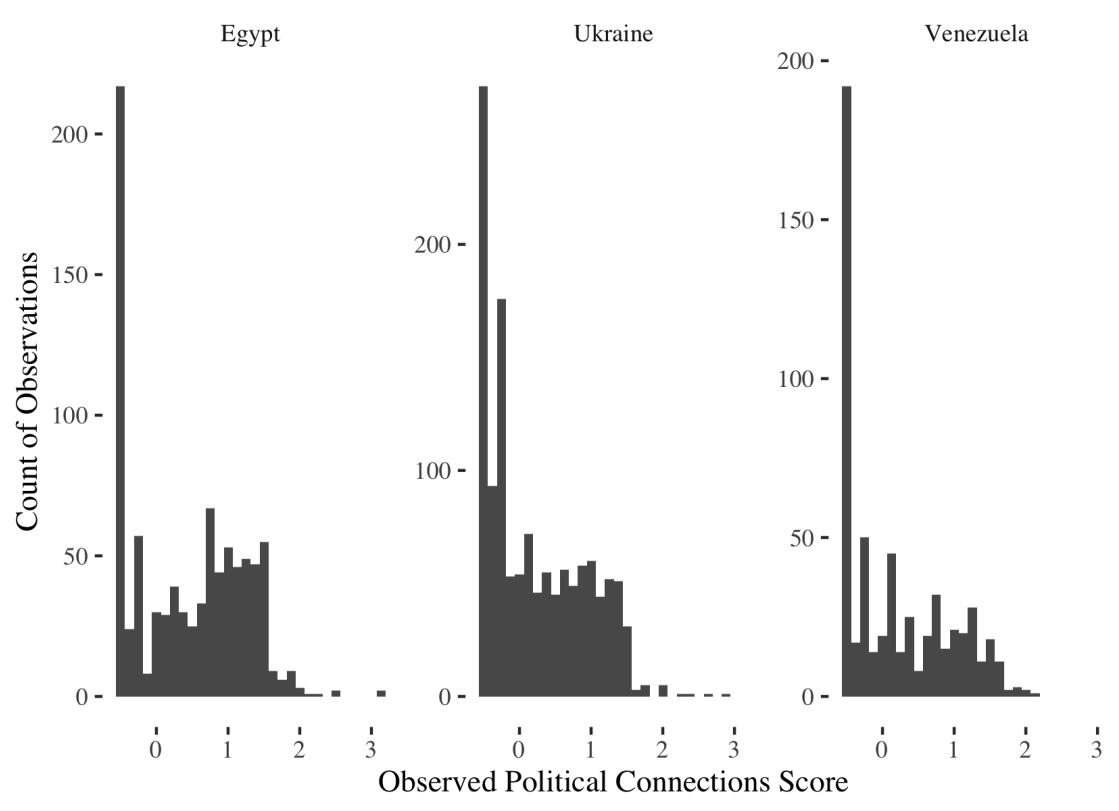

Figure 5: Histogram by Country for IRT Observed Political Connections Score

reported political connections score and the IRT-produced observed political connections score are shown in Figures 4 and 5. As can be seen, the distributions are relatively similar across countries, with pronounced modes at 0 for companies without any self-reported or observed political connections. One interesting empirical fact is that the Venezuela distribution for self-reported connections has a pronounced bi-modal distribution, while the Egyptian and Ukrainian distributions show more variation in the middle of the political connection categories.

\section{Results and Discussion}

Our main specification is a Bayesian logit model for the outcome of whether a company shut down due to COVID-19-related issues. We fit the model with the $\mathrm{R}$ package brms using default weakly informative priors (Bürkner 2017; Carpenter, Gelman, Hoffman, Lee, Goodrich, Betancourt, Brubaker, Guo, Li and Riddell 2017). The primary advantage of using a Bayesian logit model as opposed to a more conventional estimator is the ability to avoid issues of perfect separation and to permit more straightforward derivation of marginal effects 
and other useful quantities of interest.

We fit three separate models with varying numbers of controls, one set for each type of measurement of political connections: the self-reported 1 to 10 scale and the IRT scale based on observed company-state linkages. In the first model we only include country and sector (2-digit NACE codes) fixed effects along with these predictors to estimate a straightforward bivariate (or nearly so) regression model. We then also fit a model with a number of control variables, including firm profit margin in the prior year, whether the company belonged to a conglomerate, and the type of company (domestic, foreign, unregistered domestic, etc). Finally, we also fit a model adding firm size proxied by the number of employees as a control.

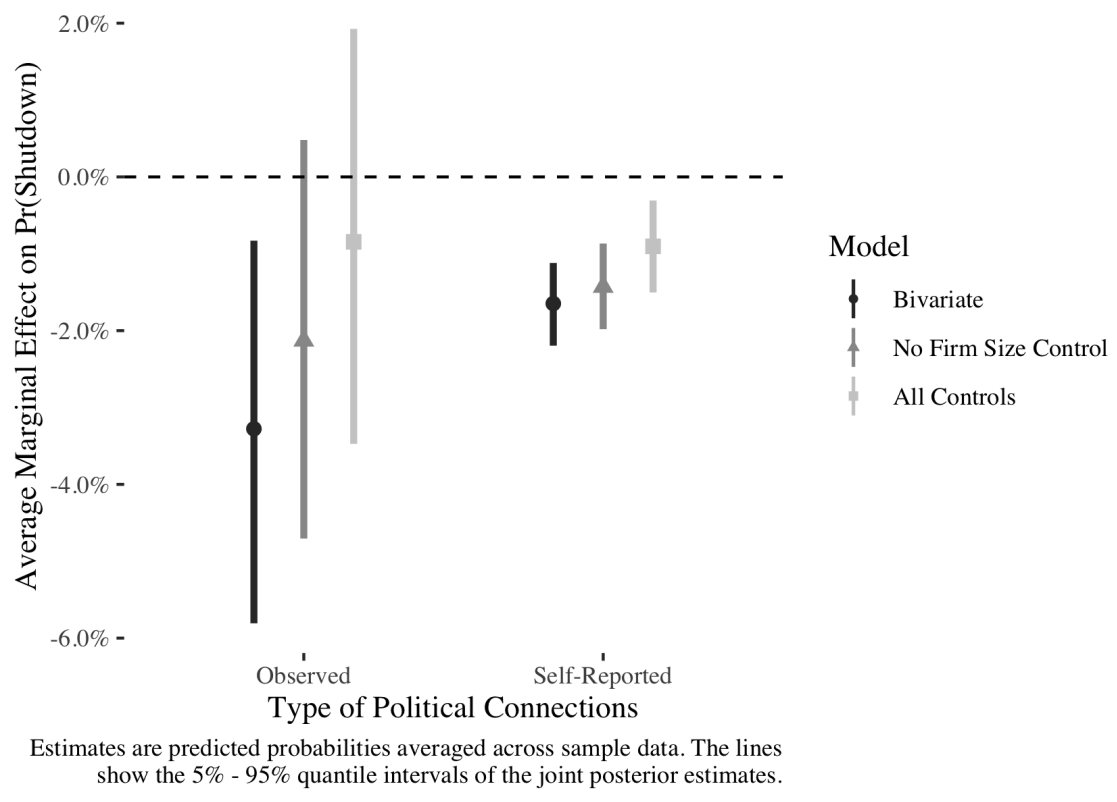

Figure 6: Average Marginal Effects for Political Connection Scores

We report the effects of the two political connections variables across the three different models in Figure 6. The effects are reported as sample-average marginal effects and so the results can be interpreted as the percent marginal increase in probability of a company shutting down due to COVID-19 given a one-unit increase in the political connections scores. In general, both observed and self-reported political connections tend to reduce the probability 
A

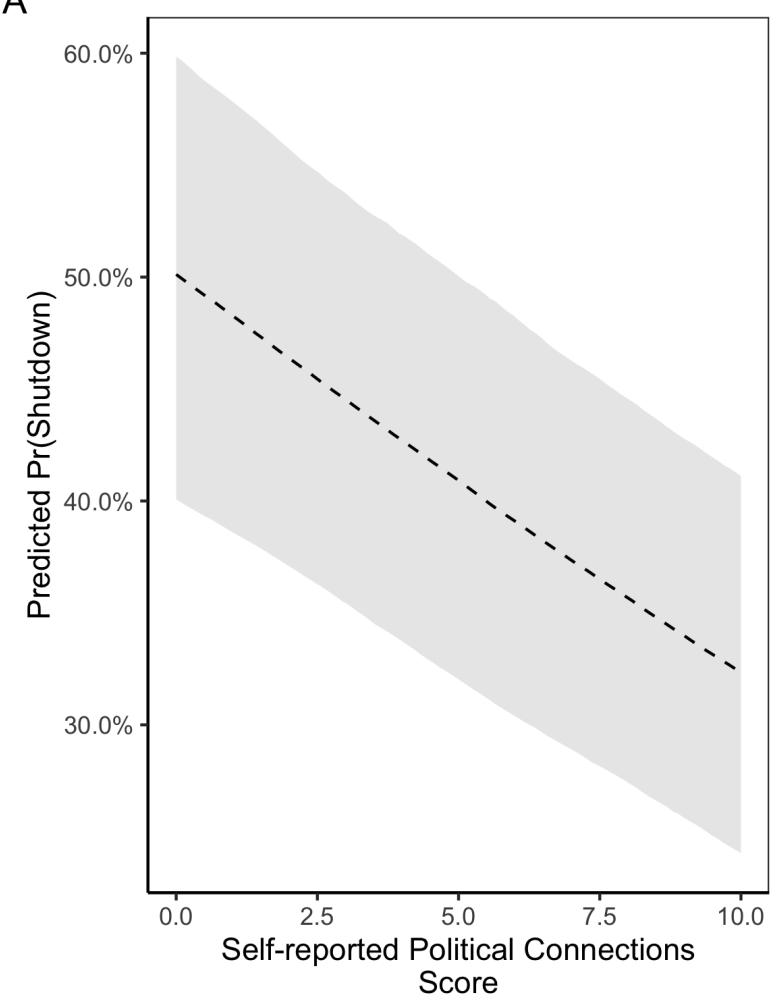

B

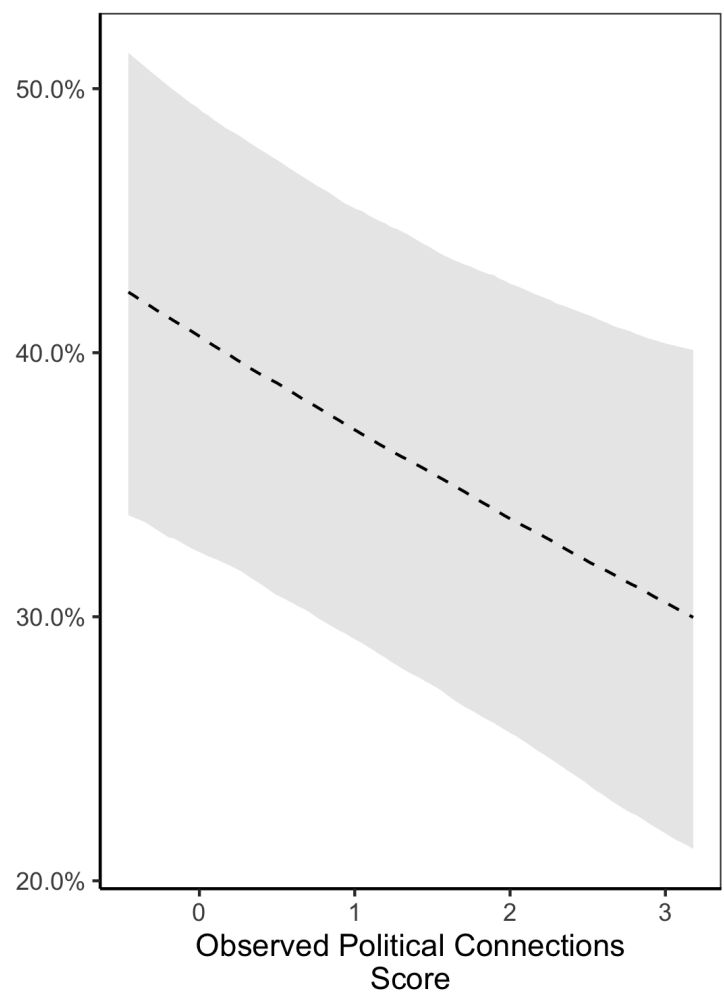

Blue ribbon shows the $5 \%$ to $95 \%$ quantiles of the posterior density of predicted chance of shutting down due to COVID-19. Dotted line is the median posterior estimate. Estimates derived from Markov Chain Monte Carlo with Stan.

Figure 7: Predicted Probability of Shutting Down for Political Connections (Bivariate Models)

of a company shutting down. For a 1-unit increase in the observed political connections score (equivalent to a 1-SD change as the score is standardized), a company is about 4 percent less likely to shut down due to COVID-19 in the bivariate model with fixed effects. For a 1-unit increase in the self-reported connections score, a company is 2 percent less likely to shut down due to COVID-19. It should be noted that though the absolute size of the effect for the observed political connections variable is larger, this is partly a scaling effect as the observed connections score runs from approximately -2 to +2 while the self-reported political connections score can take on a value from 0 to 10 . As such, a company with a 0 self-reported score would be about 20 percent less likely than a company with a 10 self-reported score to shut down due to COVID-19 in the bivariate model. Figure 7, which shows predicted 
COVID-19 shutdown rates given values of the two political connection scores, makes the strength of the relationship clearer between the two variables.

A similar pattern can be observed across the two types of measurements for political connections: the effect is the strongest in the bivariate model, and is smaller in the models with all controls and without firm size as a control. Furthermore, the uncertainty intervals indicate that the observed political connections variable is significantly noisier than the self-reported political connection variable. In the specifications with controls, the observed connections variable does not have a clear relationship with the outcome for this reasoni.e., the point estimate is a null effect, but the wide uncertainty interval suggests the true effect could be zero, positive or negative. Yet compared to the bivariate model, the observed political connections variable clearly has a weaker effect on company shutdowns in models with controls. While the self-reported variable shows a negative relationship with shutdowns in the models with controls, the effect size is noticeably smaller. We probe this empirical pattern later in this section to understand how the controls affect the relationship between connections and shutdowns.

We report sample-average marginal effects for firm sector in Figure 8 and for firm profit margin in Figure 9. The reference sector for Figure 8 is agriculture, and as such companies in most other sectors were more likely to shut down with the exception of people working in water (i.e. utilities) and transportation, both essential sectors. By comparison, respondents in education and entertainment were nearly 40 percent more likely to shut down even when accounting for political connections and other controls. This finding corresponds to our expectation that high-contact sectors like education and entertainment were more vulnerable to COVID-19 restrictions and thus more likely to shut down.

We show the sample average marginal effects for firm performance in Figure 9. The baseline category for this categorical variable is a profit margin of 0-5\%, i.e., companies that were weakly profitable. These effects do not show a perfectly monotonic pattern, though it is clear that companies that experienced greater losses in the year prior to the pandemic were 


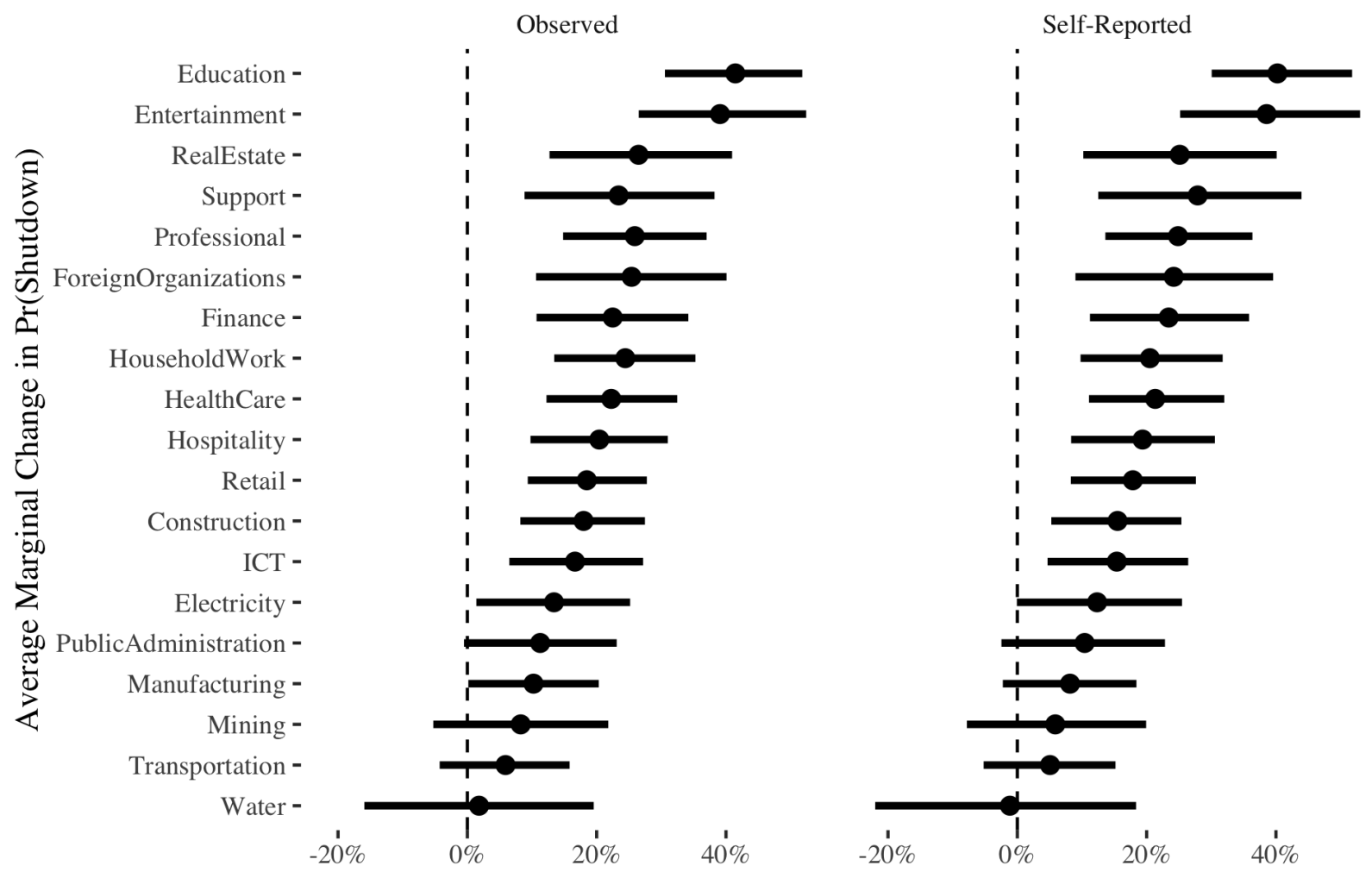

Estimates are predicted probabilities averaged across sample data. The lines show the $5 \%-95 \%$ quantile intervals of the joint posterior estimates.

Figure 8: Average Marginal Effects on Shutting Down for Firm Sector (Agriculture as Reference Category)

subsequently more likely to shut down due to COVID-19 restrictions. Again, this finding corresponds to what we might expect as companies with higher profit margins likely had more cash on hand and were better positioned to survive a lengthy shutdown.

We now return to the finding reported earlier about the dilution of the effect of political connections with controls. As can be seen by comparing the models without controls versus all controls, the dilution in the effect of political connections is primarily due to the inclusion of firm size as a control. We believe this is due to the fact that larger firms tend to be both more politically connected in our data and are also more likely to stay open during the pandemic. Figure 10 shows predicted COVID-19 shutdown rates by firm size taken from the model with all controls. As can be seen, there is a very robust relationship with larger firms 


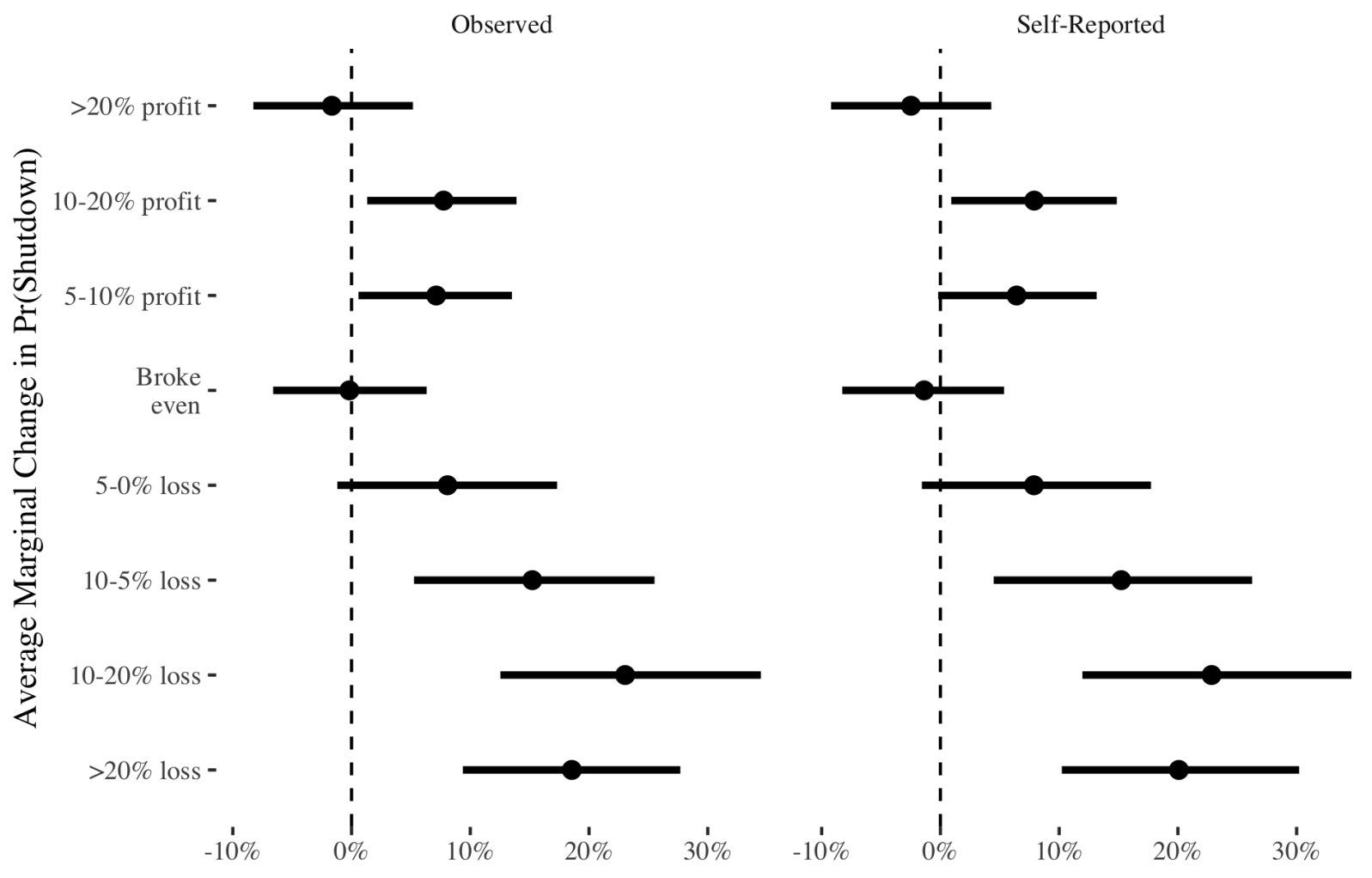

Estimates are predicted probabilities averaged across sample data. The lines show the 5\%-95\% quantile intervals of the joint posterior estimates.

Figure 9: Average Marginal Effects on Shutting Down for Firm Performance in Prior Year

more likely to stay open than smaller firms.

The question in interpreting this finding is whether firm size is here a confounding variable-it can explain both political connections and resistance to COVID-19 shutdown rates-or whether it is a so-called post-treatment variable, i.e. it is an effect of political connections. We adopt the second interpretation based on prior research about politically-connected firms and knowledge about the countries in which we did this study (Saeed, Belghitar and Clark 2015; Kang 2002; Faccio 2010; Khwaja and Mian 2005). Due to issues with corruption, poor governance and the difficulty companies have in obtaining necessary permits to operate, it is very unlikely that companies in Ukraine, Egypt or Venezuela could grow to a very large size without having political connections. As such, when we are comparing across large firms, we are very unlikely to observe any large firms without political connections 


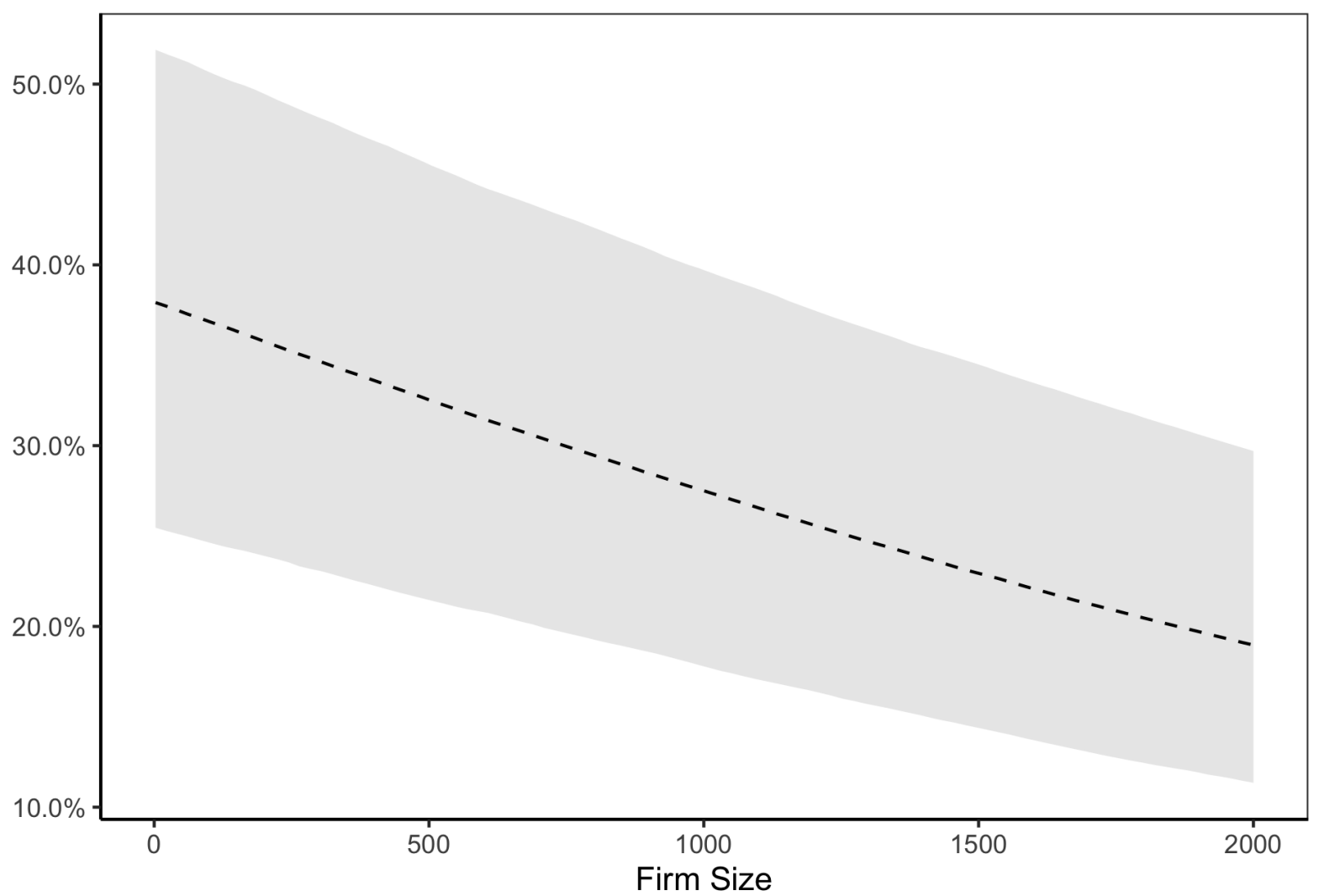

Estimates are predicted probabilities averaged across sample data. The lines show the 5\% - 95\% quantile intervals of the joint posterior estimates.

Figure 10: Predicted Probability of Shutting Down by Firm Size (All Controls Model)

due to this selection effect. Large companies without any kind of political connections would be cut apart by rivals competing for their market share and willing to exploit their own relationships to bureaucrats to throw up obstacles to competitors (Markus 2015).

In addition, firm size independent of political connections does not appear to be a very good explanation for why a company might not shut down. The effect on aggregate employment is largely the same for whether large or small companies are forced to close, and large companies may have more resources to weather a shutdown than small businesses. Absent any other reason to distinguish these companies, a policy maker would arguably prefer to pass the burden of COVID-19 restrictions onto larger established companies and spare smaller, more vulnerable companies. This is indeed the approach taken in the United States in its 
Paycheck Protection Program (PPP) loans for small businesses. ${ }^{5}$ For this reason, we believe that firm size is mediating the relationship between political connections and COVID-19 shutdown rates due to long-term selection effects in the distribution of companies.
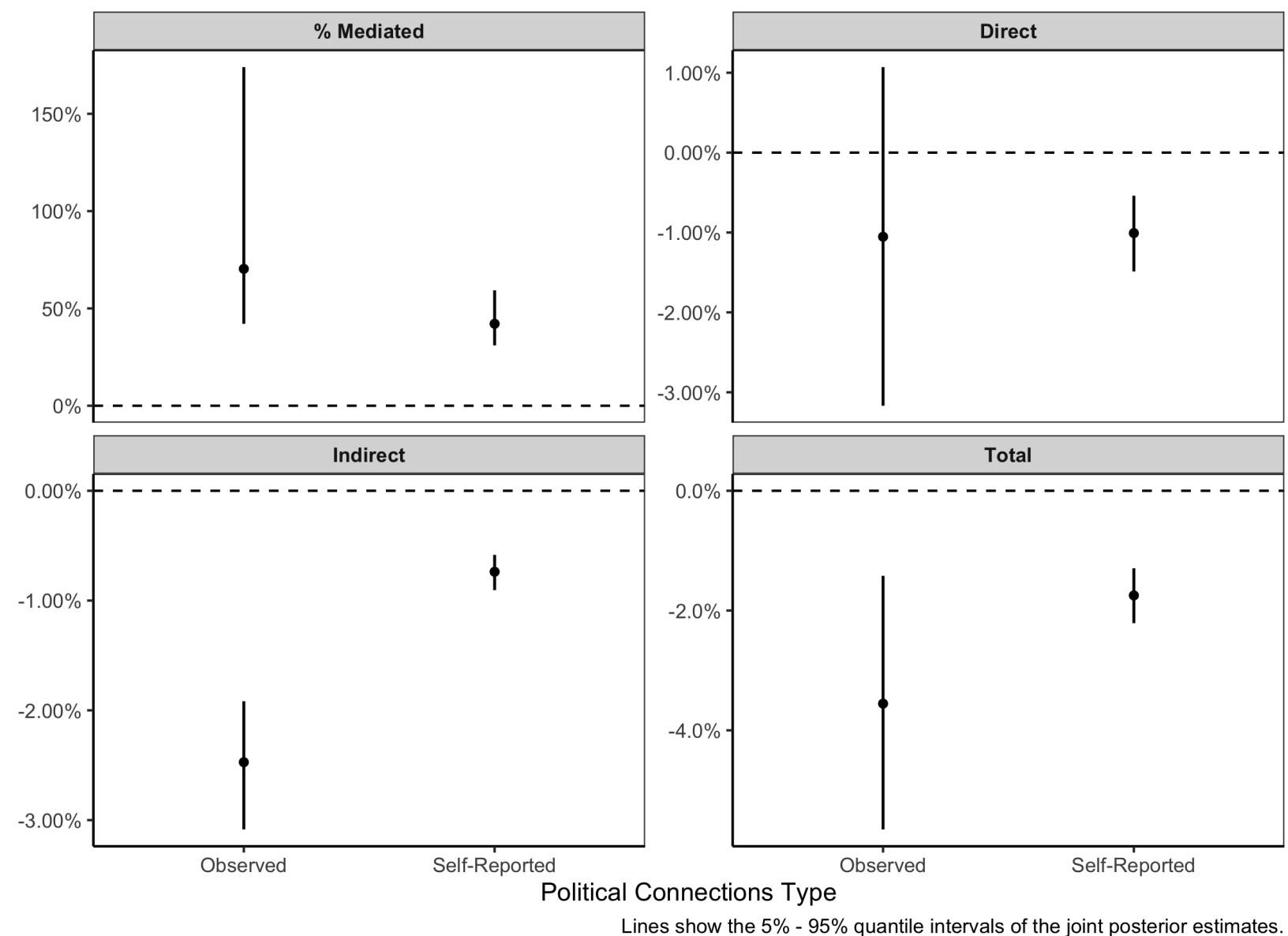

Figure 11: Mediation Analysis for Political Connections Via Firm Size

To examine this proposed mediation relationship, we implement a mediation analysis by fitting a model where we predict firm size with political connection scores and jointly fit a model with firm size and political connection scores together predicting shutdown rates. We can then use path analysis to calculate indirect, direct and total effects for political connections given the values of coefficients in both models (Yuan and MacKinnon 2009). We show these effects in addition to the proportion mediated, which is the ratio of indirect to

\footnotetext{
${ }^{5}$ See https://www.nytimes.com/2020/07/06/us/ppp-small-business-loans.html.
} 
total effects, in Figure 11. The direct effect in this figure is the same as the marginal effect from the model with firms controls reported in Figure 6. The indirect effect is the effect of political connections mediated through firm size. As can be seen, the indirect effects are quite substantial and large. They are as large as the direct effect for the self-reported score, and even larger than the direct effect for the observed score. As a result, the total effects are quite large for both the observed and self-reported scores. We note that the proportion mediated for both variables is around 50 percent, though it is even higher for the observed political connection score. It appears that firm size plays an important role in the relationship between corporate political connections and the state. Political connections facilitate company growth and consequently influence.

These also results suggest that the self-reported score is ultimately a better way to measure political connections of firms. Our aggregation of observed firm-state linkages is liable to missing relationships between companies and state officials that do not fit into one of our categories despite our efforts to capture a wide range of possibilities. The fact that the score shows so much smaller variance suggests that it better encapsulates respondents' knowledge of their companies' political connections, permitting better inferences. However, once mediation analysis is taken into account, it is very clear that both variables have a strong association with reduced COVID-19 shutdown rates.

These results provide broad support for our hypotheses. We now turn to test Hypothesis 2: companies with more political connections are less likely to implement internal policies mandating social distancing. We use a Bayesian linear model (OLS) with weakly informative priors via the brms package. Tables 2 and 3 present results. As described in the data section, we use four different variables to capture companies' internal social distancing policies namely, whether employees wear face masks, maintain 2 meters distance in the workplace, work from home, and hold no group meetings. All social distancing variables are in 3-point Likert scale, with 3 indicating that "all employees do this," 2 indicating that "some employees do this," and 1 indicating that "no one does this." 
Table 2: Effect of Self-Reported Political Connections on Company's Internal Social Distancing Policies

\begin{tabular}{|c|c|c|c|c|c|c|c|c|}
\hline & \multicolumn{2}{|l|}{ Face Mask } & \multicolumn{2}{|l|}{2 Meters } & \multicolumn{2}{|c|}{ Work from Home } & \multicolumn{2}{|c|}{ No Group Meetings } \\
\hline Predictors & Estimates & CI $(95 \%)$ & Estimates & CI $(95 \%)$ & Estimates & CI $(95 \%)$ & Estimates & CI $(95 \%)$ \\
\hline Intercept & 2.65 & $2.59-2.70$ & 2.37 & $2.30-2.44$ & 1.89 & $1.82-1.96$ & 2.31 & $2.24-2.39$ \\
\hline Political Connection (Self-Reported) & 0 & $-0.00-0.01$ & -0.01 & $-0.01-0.00$ & -0.01 & $-0.02-0.00$ & -0.02 & $-0.03--0.01$ \\
\hline Ukraine & -0.11 & $-0.16--0.05$ & -0.01 & $-0.08-0.05$ & 0.03 & $-0.04-0.09$ & -0.01 & $-0.09-0.07$ \\
\hline Venezuela & 0.19 & $0.13-0.26$ & 0.22 & $0.14-0.30$ & 0.38 & $0.30-0.46$ & 0.16 & $0.07-0.25$ \\
\hline Observations & 2497 & & 2389 & & 2401 & & 2408 & \\
\hline R2 Bayes & 0.036 & & 0.017 & & 0.042 & & 0.013 & \\
\hline
\end{tabular}

Tables 2 and 3 use the self-reported measure "political connections" and the IRT scale based on observed company-state linkages, respectively. We present simpler models just with country fixed effects in these tables but we get similar results when we include controls used to test Hypothesis 1 such as firm profit margin, firm size, firm sector, a conglomerate dummy, and the type of company. Overall, results from both tables show that there is often no meaningful association between a company's political connections and its internal social distancing policies. While substantively there is a negative association between a company's political connections and four measures of internal social distancing policies, these associations are statistically significant at 95 percent level for no group meeting policies and maintaining a distance of 2 meters. In the latter case, the effect is only substantial for observed rather than self-reported connections scores. In any case, the results are either negative or insubstantial.

Results from Tables 2 and 3 suggest that while politically connected firms are less likely to comply with COVID-19 shutdown restrictions, there is no meaningful correlation between a company's political connections and its internal social distancing policies. When such a relationship does exist, politically-connected companies are less likely to practice prudent social distancing measures such as banning in-person meetings and maintaining a distance of two meters between employees. This finding also rules out an alternative explanation to our findings that politically-connected companies are better compliers and thus it would be more prudent for policy-makers to let them remain open. 
Table 3: Effect of Observed Political Connections on Company's Internal Social Distancing Policies

\begin{tabular}{|c|c|c|c|c|c|c|c|c|}
\hline & \multicolumn{2}{|l|}{ Face Mask } & \multicolumn{2}{|l|}{2 Meters } & \multicolumn{2}{|c|}{ Work from Home } & \multicolumn{2}{|c|}{ No Group Meeting } \\
\hline Predictors & Estimates & CI $(95 \%)$ & Estimates & CI $(95 \%)$ & Estimates & CI $(95 \%)$ & Estimates & CI $(95 \%)$ \\
\hline Intercept & 2.66 & $2.62-2.70$ & 2.38 & $2.33-2.43$ & 1.86 & $1.81-1.91$ & 2.27 & $2.21-2.33$ \\
\hline political Connections (IRT) & 0.01 & $-0.02-0.05$ & -0.05 & $-0.09--0.01$ & -0.01 & $-0.05-0.03$ & -0.1 & $-0.14--0.05$ \\
\hline Ukraine & -0.1 & $-0.15--0.05$ & -0.03 & $-0.10-0.03$ & 0.02 & $-0.05-0.08$ & -0.01 & $-0.09-0.06$ \\
\hline Venezuela & 0.19 & $0.13-0.26$ & 0.19 & $0.11-0.27$ & 0.39 & $0.31-0.47$ & 0.15 & $0.05-0.24$ \\
\hline Observations & 2682 & & 2566 & & 2566 & & 2566 & \\
\hline R2 Bayes & 0.035 & & 0.018 & & 0.018 & & 0.018 & \\
\hline
\end{tabular}

\section{Conclusion}

We find that politically connected firms are significantly less likely to comply with COVID-19 shutdown restrictions. As political connections are associated with firm size, we find that the effect of connections is mediated through firm size for both of our political connections measures. These findings imply that, first, governments with weak institutions and high levels of corruption are less likely to effectively carry out public health measures in response to the COVID-19 pandemic. Since politically connected firms leverage their connections to escape public health restrictions, compliance with business-related measures is likely to be low in states with corruption levels similar to that of Ukraine, Egypt and Venezuela. Distortions and inefficiencies associated with corruption and weak institutions thus affect the severity of natural disasters and public health crises not only by weakening disaster-mitigation standards, but also by undermining disaster response policies.

Second, our findings suggest that COVID-19 restriction loopholes associated with political connections are likely to contribute to market concentration in sectors with large numbers of politically connected firms, increasing inequality more generally. Since larger firms are more likely to be politically connected, our results show that large firms are less likely to comply with business restrictions. If large, connected firms evade restrictions and stay open while smaller, unconnected firms shut down, large firms may thus capture a larger share of the market. Small and unconnected firms are more likely to be driven out of business as they weather the costs of forced shutdown, in addition to the already existing problems of government predation. This type of uneven enforcement of shutdown restrictions is likely 
to contribute to increased inequality as small firms go out of business and large firms grow larger.

These results are relevant for research on corruption, political connections, public health, and disaster response. While most of the research on corruption and natural disasters focuses on factors that increase the destructiveness of disasters involving physical forces, such as earthquakes or hurricanes, our findings show that corruption and weak institutions affect response to events like pandemics that do not involve direct physical destruction. More firm-level research is needed to understand how corruption and political connections impact government disaster response. How do politically connected firms benefit from disaster recovery assistance? Do connection types matter? How do these relations vary across types of natural events? Answers to these questions would be highly useful in understanding government-business interactions during and in the wake of natural disasters.

Our research suggests some additional avenues for future work. Our findings imply that inconsistencies in lockdown enforcement may lead to increased inequality and market concentration. While we are unable to test this hypothesis directly, future work ought to more closely examine the relationship between inequality, politically connected firms and market structure. If politically connected firms capture larger market shares through access to a club good, such as lax enforcement of public health measures, high prevalence of politically connected firms is likely to be associated with more monopoly and oligopoly. More research is need to more fully understand if and how corruption affects inequality and the concentration of capital in high-corruption states. 


\section{References}

Adams-Prassl, Abi, Teodora Boneva, Marta Golin and Christopher Rauh. 2020. "Inequality in the Impact of the Coronavirus Shock: Evidence from Real Time Surveys." Journal of Public Economics 189:104245.

Ambraseys, Nicholas and Roger Bilham. 2011. "Corruption kills." Nature 469(7329):153-155.

Anbarci, Nejat, Monica Escaleras and Charles A. Register. 2005. "Earthquake fatalities: the interaction of nature and political economy." Journal of Public Economics 89(9):1907-1933.

Atkinson, James, Allen Hicken and Nico Ravanilla. 2014. Pork and Typhoons: The Influence of Political Connections on Disaster Response. Number ID 1911915.

URL: https://papers.ssrn.com/abstract $=1911915$

Bartik, Alexander W., Marianne Bertrand, Zoe Cullen, Edward L. Glaeser, Michael Luca and Christopher Stanton. 2020. "The impact of COVID-19 on small business outcomes and expectations." Proceedings of the National Academy of Sciences 117(30):17656-17666.

URL: https://www.pnas.org/content/117/30/17656

Bonaccorsi, Giovanni, Francesco Pierri, Matteo Cinelli, Andrea Flori, Alessandro Galeazzi, Francesco Porcelli, Ana Lucia Schmidt, Carlo Michele Valensise, Antonio Scala, Walter Quattrociocchi and Fabio Pammolli. 2020. "Economic and Social Consequences of Human Mobility Restrictions under COVID-19." Proceedings of the National Academy of Sciences 117(27):15530-15535.

Brodeur, Abel, David Gray, Anik Islam and Suraiya Jabeen Bhuiyan. 2020. "A Literature Review of the Economics of COVID-19." IZA Institute of Labor Economics Discussion Paper Series .

URL: https://papers.ssrn.com/sol3/papers.cfm?abstract_id=3636640

Bürkner, Paul-Christian. 2017. "Brms: An R Package for Bayesian Multilevel Models Using Stan." Journal of Statistical Software 80(1):1-28.

Carpenter, Bob, Andrew Gelman, Matthew D. Hoffman, Daniel Lee, Ben Goodrich, Michael Betancourt, Marcus Brubaker, Jiqiang Guo, Peter Li and Allen Riddell. 2017. "Stan: A Probabilistic Programming Language." Journal of Statistical Software 76.

Cheng, Cindy, Joan Barcelo, Allison Spencer Hartnett, Robert Kubinec and Luca Messerschmidt. 2020. "COVID-19 Government Response Event Dataset (CoronaNet v.1.0)." Nature Human Behavior .

Claessens, Stijn, Erik Feijen and Luc Laeven. 2008. "Political connections and preferential access to finance: The role of campaign contributions." Journal of financial economics 88(3):554-580.

Diwan, Ishac, Philip Keefer and Marc Schiffbauer. 2015. Pyramid Capitalism: Political Connections, Regulation, and Firm Productivity in Egypt. Policy Research Working Paper 7354 World Bank.

Escaleras, Monica, Nejat Anbarci and Charles Register. 2007. "Public sector corruption and major earthquakes: A potentially deadly interaction." Public Choice 132(1):209-230.

Faccio, Mara. 2010. "Differences between Politically Connected and Nonconnected Firms: A Cross-Country Analysis." Financial Management 39(3):905-927.

Faccio, Mara, Ronald W Masulis and John J McConnell. 2006. "Political connections and corporate bailouts." The Journal of Finance 61(6):2597-2635.

Fisman, Raymond. 2001. "Estimating the value of political connections." American economic review 91(4):1095-1102. 
Gallego, Jorge A., Mounu Prem and Juan F. Vargas. 2020. Corruption in the Times of Pandemia. SSRN Scholarly Paper ID 3600572 Social Science Research Network Rochester, NY: .

Kang, David C. 2002. Crony Capitalism: Corruption and Development in South Korea and the Philippines. Cambridge Studies in Comparative Politics Cambridge: Cambridge University Press.

Khwaja, Asim Ijaz and Atif Mian. 2005. "Do Lenders Favor Politically-Connected Firms? Rent Provision in an Emerging Financial Market." The Quarterly Journal of Economics 120(4):1371-1411.

Markus, Stanislav. 2015. Property, Predation and Protection: Piranha Capitalism in Russia and Ukraine. Cambridge University Press.

Saeed, Abubakr, Yacine Belghitar and Ephraim Clark. 2015. "Political Connections and Leverage: Firm-Level Evidence from Pakistan." Managerial and Decision Economics 36:364-383.

Shleifer, Andrei and Robert W Vishny. 1993. "Corruption." The quarterly journal of economics 108(3):599617.

Whittaker, Charlie, Anna Frühauf, Samuel John Burthem, Rebecca Shoshanah Parry, Meghana Kotikalapudi, Yihui Liang, Mary Moffett Barker, Parth Rohit Patel and Ilan Kelman. 2018. "A disaster diplomacy perspective of acute public health events." Disasters 42(S2):S173-S195.

Yuan, Ying and David P. MacKinnon. 2009. "Bayesian Mediation Analysis." Psychological methods 14(4):301-322. 